\title{
Comparing Contract Administration Functions for Alternative and Traditional Delivery of Highway Projects
}

\author{
Dean Papajohn, Ph.D., P.E, M.ASCE${ }^{1}$, Mounir El Asmar, Ph.D., A.M.ASCE ${ }^{2}$,
}

$$
\text { Keith R. Molenaar, Ph.D., M.ASCE }{ }^{3} \text {, Doug Alleman, P.E., S.M.ASCE }{ }^{4}
$$

${ }^{1}$ Associate Professor of Practice, Dept. of Civil \& Architectural Engineering and Mechanics, Univ. of Arizona, 1209 E. Second St., Tucson, AZ 85721-0072 (corresponding author). ORCID: https://orcid.org/0000-0003-2364-838X. Email: dpapajohn@email.arizona.edu

${ }^{2}$ Associate Professor and Senior Sustainability Scientist, School of Sustainable Engineering and the Built Environment, Arizona State Univ., 660 S. College Ave., P.O. Box 873005, Tempe, AZ 85287-3005.

Email: asmar@asu.edu

${ }^{3}$ Professor, Dept. of Civil, Environmental, and Architectural Engineering, Univ. of Colorado, 428 UCB, 1111 Engineering Dr., Boulder, CO 80309-0428. Email: keith.molenaar@colorado.edu

${ }^{4} \mathrm{Ph} . \mathrm{D}$. Student, Construction Engineering and Management, Dept. of Civil Environmental and Architectural Engineering, Univ. of Colorado, 428 UCB, Boulder, CO 80309-0428 Email: doal7544@colorado.edu

Abstract: Agency roles and responsibilities for contract administration depend on the contracting method. The Federal Highways Administration (FHWA) has encouraged agencies to consider alternative contracting methods (ACMs) like design-build (DB) and construction manager/general contractor $(\mathrm{CM} / \mathrm{GC})$. There is a lack of information available to transportation agencies regarding the details of agency performed contract administration functions between ACMs and traditional design-bid-build (DBB) delivery. This paper contributes to the existing body of knowledge of highway contract administration by revealing similarities and differences between agency performed contract administration functions across contracting methods through the development of Integrated DEFinition function models (IDEF0). These IDEF0 models depict the hierarchy of contract administration functions for DBB, CM/GC, and DB highway projects and reveal differences such as developing alignment, administering preconstruction services, managing work packages, and creating risk pools for additional scope. The findings can help agencies make more informed decisions about selecting and administering contracting methods, especially as it relates to establishing the level of effort and skills needed for administering projects 
under various contracting methods. Additionally, these IDEF0 models provide a novel framework for future research on highway contract administration.

\section{BACKGROUND}

The United States has a long history of implementing DBB, including the establishment of the Interstate Highway system. The use of ACMs like CM/GC and DB has expanded in recent years (Minchin et al. 2014) as federal and state legislation has broadened to allow their use. The timeline of significant federal ACM legislation and initiatives is summarized in Figure 1. FHWA (2016) encourages the use of ACMs "to accelerate project delivery, encourage the deployment of innovation, and minimize unforeseen delays and cost overruns." Not all states have used ACMs. By 2014, 35 states had some level of experience with DB and 17 states had used CM/GC (FHWA 2018). The relatively new use of ACMs compared with DBB and the lack of comprehensive guidance on ACM contract administration led the National Cooperative Highway Research Program to initiate research for a guidebook on ACM contract administration (NCHRP 2016). This research paper seeks to address the knowledge gap regarding the similarities and differences between DBB, CM/GC, and DB highway contract administration functions.

DBB separates the contractor from the design process, and the agency holds separate contracts for construction and design (or employs in-house design). CM/GC (sometimes referred to as Construction Manager at Risk (CMAR)) engages the contractor during the design phase through a preconstruction services contract. Similar to $\mathrm{DBB}$, in $\mathrm{CM} / \mathrm{GC}$ there are separate contracts for design and construction. When a price proposal is accepted and construction begins, the $\mathrm{CM} / \mathrm{GC}$ contractor switches to the role of general contractor. In DB, the agency holds a single contract for design and construction (FHWA 2018, TRB 2009). Different delivery methods offer different contractual complexity affecting control, coordination, and adaptation (Wang et al. 2018) 
and different contractual governance affecting cooperation (Quanji et al. 2017). Also, contract administration is impacted by governmental regulations (El-adaway at al. 2018) and even within a country like the United States, state and local regulations may differ on the use of ACMs.

Numerous research studies have compared the performance of contracting methods on highway projects (e.g., Gransberg and Molenaar 2019; Molenaar and Franz 2019; Antoine et al. 2018; Chini et al. 2018; Tran et al. 2018b; Shrestha et al. 2012; FHWA 2006; Molenaar 2003 ). Yet these comparisons do not investigate the differences and similarities of contract administration functions nor their potential impacts on project delivery. Poor contract administration can lead to disputes (Abotaleb et al. 2019). Contract administration functions are the tasks agencies must do to fulfill their contract responsibilities and to facilitate project progress to completion.

The next section presents the research objective. Then a summary of state agency manuals and the research literature on ACMs is presented. Next, a process modeling method called Integrated DEFinition function modeling (IDEF0) is described followed by an explanation of the research methods. Then the results of IDEF0 modeling for DBB, CM/GC, and DB are shared as node indices and in IDEF0 hierarchy form. After that, the three IDEF0 models are analyzed and discussed. Conclusions are summarized at the end.

\section{RESEARCH OBJECTIVE}

The objective of this paper is to identify the contract administration functions performed by agencies for DBB, CM/GC, and DB through hierarchical IDEF0 modeling based on input from industry professionals. No detailed models for the contract administration functions for these three delivery methods were found in the literature. Models of contract administration functions allow for in-depth analyses of similarities and differences across delivery methods. The detailed process models have practical applications in the staffing of projects. Agencies can consider the specific 
functions that are part of ACM project delivery as revealed in the IDEF0 models, and consider the skills needed by their staff to perform those functions. Additionally, the IDEF0 models of contract administration functions can serve as a foundation for future research on delivery methods.

\section{STATE Of PRACTICE: STATE AGENCY MANUALS}

Researchers and practitioners have shown a broad interest in alternative contracting methods. This section looks at the ACM manuals currently available in state transportation agencies. These manuals demonstrate the growing use of ACMs and the need to better understand how to successfully perform ACM contract administration.

Federal legislation (Moving Ahead for Progress in the 21st Century Act 2012) states, "Congress declares that it is in the national interest to promote the use of innovative technologies and practices that increase the efficiency of, construction of, improve the safety of, and extend the service life of highways and bridges" and goes on to cite DB and CM/GC contracting methods specifically. As the federal government has been encouraging states to implement ACMs, many states have responded by passing legislation authorizing ACMs and developing ACM guidance manuals. In 2017 the authorization for DB delivery of transportation projects was either widely permitted or fully authorized in 34 of 52 agencies (DBIA 2017). For the delivery of CM/GC transportation projects, 20 of the 50 states plus the District of Columbia and FHWA have some form of legislation. Table 1 summarizes the manuals produced by state transportation agencies.

Most of these manuals include a section on the benefits of various delivery methods and considerations in the selection of a delivery method. However, the staffing, training, and tools to perform contract administration in ACMs is covered minimally or not at all. Many of these manuals as well as researchers looking into ACMs have noted the need for a cultural or perspective change when an agency immersed in DBB begins to implement ACMs. Minchin et al. (2014) noted 
that for DB, "the approach to manage design activities is also uniquely different from traditional $D B B$ delivery" and for CM/GC "It is very important for those considering implementing $C M / G C$ to consider the cultural shift that has to take place if one (agency or individual) has never worked on a CM/GC project before." This suggests that new processes suited for ACM contract administration are needed.

\section{LITERATURE ON ALTERNATIVE DELIVERY}

The research on alternative delivery is rich in delivery method selection and project delivery performance, but there is a gap in the research on ACM contract administration for highway projects.

In the literature on delivery method selection, contract administration functions have either been overlooked or not directly linked to staffing needs. As early as 1985, nine criteria for project delivery selection were identified, including: time, certainty of time, certainty of cost, price competition, flexibility, complexity, quality, responsibility, and risk (NEDO 1985), but none of these criteria link directly to staffing variables. Over the years, researchers have used these criteria (e.g., Skitmore \& Marsden 1998) and expanded on them (e.g., Luu et al. 2005; Gordon 1994). Gordon (1994) increased the number of variables to 13 and grouped them into: project drivers, owner drivers, and market drivers. While contract administration functions are not mentioned explicitly, Gordon (1994) did acknowledge the changing role and functions of an agency with different delivery methods when he stated, "Different contracting methods require different levels of involvement." This need for agencies to implement changes in order to implement ACMs is referred to in the research literature as introducing a change in culture, philosophy, and practice compared to the traditional DBB (Minchen et al. 2014; Pietroforte and Miller 2002; Molenaar and Gransberg 2001; Miller et al. 2000). 
Researchers have developed various lists of criteria for project delivery selection. Alhazmi and McCaffer (2000) identified twenty-five client needs combined with a framework of project characteristics, market attributes, contractor needs, local construction regulations, client design organization, and client categories. Luu et al. (2005) grouped twenty-one project selection criteria into three categories: client characteristics and objectives, project characteristics, and external environment. Tran et al. (2016) focused on risk for delivery method selection variables of highway projects and identified multiple risks for $\mathrm{DBB}, \mathrm{CM} / \mathrm{GC}$, and DB. Contract administration functions were not explicitly mentioned in any of these lists.

Tran et al. (2013) presented a selection matrix based on eight variables: delivery schedule, complexity and innovation, level of design, initial project risk assessment, staff experience/availability, level of oversight and control, and competition and contractor experience. This framework became the basis for Colorado's Project Delivery Selection Matrix (CDOT N.D.). Alleman et al. (2017b) summarized the selection criteria identified in twenty-two state ACM manuals. The variables most closely related to contract administration functions are: owner staff experience and availability (mentioned in ten states), and level of oversight and control (mentioned in two states). The variables of owner staff experience/availability and level of oversight and control support the premise that the level of effort and skills for contract administration functions differ across delivery methods.

Research in the area of ACM contract administration is limited. Processes like constructability which are used with ACMs have been researched (Trigunarsyah 2004; Fisher et al. 2000), but their work is not set in the context of ACMs. Researchers who have explored contract administration have typically focused on contract language, risks, and dispute avoidance (Abotaleb et al. 2019; El-adaway et al. 2018; Chong et al. 2011) but this does not address the specific 
functions agencies perform to administer contracts. Others have described processes for contract administration (Phillips 1999; Thomas et al. 1980; Scott 1974) but these are not specific to ACMs. The limited reference to contract administration functions in project delivery selection and the absence of research on ACM contract administration points to a knowledge gap in highway contract administration.

\section{OVERVIEW Of INTEGRATED DEFINITION FUNCTION MODELING (IDEFO)}

Integrated DEFinition function modeling (IDEF0) is a graphical, hierarchical structure for modeling system functions and has been used widely in construction research (e.g., Anderson et al. 2015; Erdogan et al. 2014; Tang and Bittner 2014; Akinci et al. 2006; Fisher et al. 2000). IDEF0 graphically depicts relationships within and between hierarchical levels. IDEF0 modeling offers insight into the parts of a process and the connections between those parts. The IDEF0 model was selected for this research because it: 1) communicates functions graphically; 2) represents the detailed levels within functions through hierarchical modeling; and 3) was successfully applied to previous research in construction.

Practitioners and researchers have applied the IDEF0 technique to a number of construction research studies. Users of the family of IDEF models 0 through 5 include the US Air Force (NIST 1993; Mayer 1990), the US Department of Defense, and many corporations (KSBI N.D.a). The Minnesota Department of Transportation used IDEF0 modeling to deconstruct their departmental cost estimation and cost management processes (MnDOT 2008). IDEF0 modeling has been used successfully by researchers for modeling building design processes (Sanvido and Norton 1994), pre-project planning processes (Gibson et al. 1995), constructability review processes (Fisher et al. 2000), organizational change in construction companies (Erdogan et al. 2014), and project scoping processes for transportation projects (Anderson et al. 2015). Akinci et al. (2006) used the 
IDEF family of methods to model information flow on construction sites. The successful use of the IDEF family of models in construction demonstrates the relevance and value of this type of modeling.

IDEF0 models are composed of arrows and nodes. The left side of Figure 2 depicts the main components of an IDEF0 model. Functions are activities that transform inputs into outputs. Input arrows connect to the left of each node and represent data or objects that are transformed by the function. Output arrows connect from the right of each node and represent data or objects resulting from a transformation. Control arrows connect to the top of each node and represent conditions or constraints that impact transformations. Mechanism arrows connect to the bottom of each node and represent a means, such as a person or tool to perform a function.

Hierarchical levels can be depicted with IDEF0 modeling by linking subfunctions with functions. In Figure 2 the label A0 in the bottom right corner of the node indicates that this belongs to project A, at the top or zero level. The labels A1 and A2 indicate that these are subfunctions in level 1 (a single numeric digit after A). All inputs, controls, outputs, and mechanisms at the zero level must also be connected with one or more subfunctions in the first level and so on for each level/sublevel pair. If subfunction 1 had subsubfunctions, they would be labeled A11, A12, A13, and so on.

IDEF0 as a modeling tool has advantages and disadvantages (KSBI N.D.b). The advantages relate to its proven application and ability to describe in detail the activities of a system including inputs, controls, outputs, and mechanisms (ICOM). In IDEF0 terminology, activities are functions that transform inputs (e.g., contracts, scope changes, unforeseen conditions) into outputs (e.g., work packages, contract modifications), in the context of controls (e.g., standards and permits) and mechanisms (e.g., tools and resources). The hierarchical structure allows for 
additional levels of detail to suit the needs of a particular analysis. IDEF0 can be applied to "asis" modeling of existing systems (which is the case for this study on delivery methods) as well as "to-be" modeling of systems under development. Additionally, models can be built from the bottom up, but be viewed from the top down (starting with broad functions and drilling deeper to subfunctions). Disadvantages relate to the high level of detail and perceived sequence. In some situations, IDEF0 modeling can become extremely detailed, and thus only understandable to experts in the discipline and those involved in development of the model. Also, although IDEF0 is drawn from left to right with arrows linking various functions, it does not depict a time sequence. When IDEF0 is understood and applied appropriately, it has proven to be an effective tool for modeling system functions.

\section{RESEARCH METHOD}

The research methodology used to develop IDEF0 models that identify contract administration functions is summarized in five steps below. The DB model was developed first, followed by the $\mathrm{CM} / \mathrm{GC}$ and DBB models. Seven industry professionals served as informants to develop the IDEF0 models. Table 2 summarizes the experience of the industry professionals. The criteria for selecting informants was ten or more years of experience with delivery of federal or local transportation projects. The group of industry professionals reflects experience in agency, contractor, and research domains. Example IDEF0 models and further explanation of the hierarchical levels is presented in the next section called Resulting IDEF0 Models of ACM Processes.

\section{Step 1 Identify Contract Administration Functions}

Multiple in-depth interviews were conducted with one of the industry professionals. During a DB model interview, the researchers asked the industry professional to identify and describe activities a transportation agency performs to administer a DB contract (and agency activities for CM/GC 
during the $\mathrm{CM} / \mathrm{GC}$ interview). The researchers probed for underlying activities to develop an understanding of the hierarchy of contract administration activities. Additionally, major controls that constrain a function were identified as well as the mechanisms, used to accomplish the function. Contrasts to DBB contract administration were also noted.

\section{Step 2 Draft Preliminary IDEFO Models}

The data collected from the industry professional was used to draft a preliminary IDEF0 model using IDEF0 software with node and arrow syntax. The IDEF0 model contains multiple levels with lower levels linked to upper levels.

\section{Step 3 Check Preliminary IDEFO Models}

Each of the preliminary IDEF0 models was shown to two or more industry professionals, including the industry professional involved in step one. The researchers and the practitioner reviewed together in detail each element of the model, examining the contract administration functions performed by an agency and how the functions are related. Feedback from the industry professional regarding additional details, clarifications, and adjustments were noted by the researchers. All feedback was used as input to revise the models. No significant disagreements from different industry professionals were raised during the interviews. When feedback was specific to a particular project or organization, the researchers confirmed this point with the industry professional and did not include this in the modeling.

\section{Step 4 Finalize IDEFO Models}

The industry professionals' feedback was used to revise the IDEF0 model to produce a final version. A DBB IDEF0 model was developed based on the DB and CM/GC IDEF0 models and the contrasts to DBB identified by practitioners.

\section{Step 5 Analyze IDEFO Models}


The IDEF0 models for DBB, CM/GC, and DB were compared at each of the hierarchical levels in the models and differences and similarities in contract administration functions were noted.

\section{Summary of Model Validation}

The credibility of process models is enhanced when validity is increased, respondent bias is decreased, and generalizability is increased. Validity is the extent to which a model captures the elements of the real process being modeled (Law and Kelton 2000; Shannon 1998). Validity of the IDEF0 model is increased through the input of industry professionals during structured walkthroughs (Sargent 2013). Lucko and Rojas (2010) suggest that involvement of domain experts is a strong way to establish validity. Validity was further strengthened when the phases and functions from the model were effectively used as the structure for $30 \mathrm{ACM}$ case study interviews with 91 agency personnel from 17 agencies (Arizona (ADOT), California (Caltrans), Colorado (CDOT), Florida (FDOT), Federal Highways-Central Federal Lands District (FHWA-CFLD), Georgia (GDOT), Michigan (MDOT), Maryland State Highway Administration (MDSHA), Missouri (MoDOT), Minnesota MnDOT, North Carolina (NCDOT), New York State (NYSDOT), Pennsylvania (PennDOT), Utah (UDOT), Virginia (VDOT), Vermont (VTrans), Washington State (WSDOT) for a National Cooperative Highway Research Program study (NCHRP 2016). External validity is related to how well results can be generalized outside the sample studied (Lucko and Rojas 2010). For this study, initially the transportation agencies in all 50 states, the District of Columbia, and FHWA were considered. However, this is not the population, since not all agencies have authorization or experience with DB and CM/GC delivery. At the time of this study, 34 of these agencies had some level of authorization for DB delivery, so 34 is the sample size for agencies using DB. Case studies for this research included 15 state agencies and one federal lands district, or 16 of the 34 agencies (47\%). This high percentage of agency representation enhances 
validity. At the time of this study, 20 of these agencies had some level of authorization for CM/GC procurement, so 20 is the sample size for agencies using $\mathrm{CM} / \mathrm{GC}$. $\mathrm{CM} / \mathrm{GC}$ case studies for this research included five state agencies and one federal lands district, or six of the 20 agencies (30\%). This too is a strong percentage of agency representation that enhances validity.

Agency personnel that were interviewed for the 30 project case studies confirmed that the contract administration functions used to structure the interviews accurately identified the processes being used by their agencies. One agency asked about including environmental compliance as a function in the CM/GC IDEF0 model. Typically, agencies are depending on the designer, perhaps with contractor input, to obtain environmental clearance, so the contract administration function is worded ensure environmental compliance and is a sub-activity of ensure design compliance (italics are used to identify administration functions from the IDEF0 model). This emphasizes the agency's oversight role versus permit application activities performed by a consultant. Training for DB and ACM contract administration was also brought up in the case study interviews, but this was determined not to be a contract administration function, rather it is an activity to help the agency develop knowledge, skills, and a unified approach to ACMs.

During the case study interviews, agencies discussed varying tools to perform the same contract administration function. For example, agencies may demonstrate unique organizational charts, project escalation ladders, or systems and software for project documentation; however, these do not change the underlying contract administration function as depicted in the IDEF0 models. One example can be observed in how agencies bring the designer and CM/GC together with the owner and other stakeholders. Some agencies hold a project kickoff meeting, some agencies hold a formal partnering meeting, and some agencies hold both. In each case, the objective is for the owner to administer alignment between project team members. These different 
meetings can be considered different tools for performing the same contract administration function. Another example of a tool that some agencies use for administering alignment is the SWOT analysis, which identifies strengths, weaknesses, opportunities, and threats. Agencies that do not use the SWOT analysis have other tools for administering alignment, so the contract administration function of administer alignment as seen in the IDEF0 model is typical in agencies. Yet another example is an innovation matrix for the $\mathrm{CM} / \mathrm{GC}$ and other team members to record and track ideas. Some agencies have a standard form to use as an innovation matrix tool and others create a project specific matrix or log. Nevertheless, in either case, the contract administration for the owner remains the same, review $C M / G C$ input for design. A final example is work packages (Alleman et al. 2017c). Some agencies try to minimize the number of work packages on CM/GC projects so as to preserve the ability to put a project out for bid if the CM/GC's price proposal is unsatisfactory. Other agencies focus on using work packages where they bring benefit to the project and work to keep each package severable from the remainder of the work. These different approaches did not change the underlying contract administration function of administer $C M / G C$ design input. Each of these examples - project kickoff meetings, SWOT analysis, innovation matrix, and work packages - demonstrate how agencies might take a different approach or implement different tools to perform an underlying contract administration function. Thus, the IDEF0 models have been developed broadly enough to be representative of typical contract administration functions.

Response bias can occur when respondents provide inaccurate information by answering in a way they believe is socially acceptable (Furnham 1986). During model development, industry professionals with extensive knowledge of delivery method processes were interviewed. Because respondents were interviewed as experts, they did not have pressure to conform their responses to 
a certain group, so the respondent bias was minimized. Furthermore, interviewing multiple respondents helped prevent undue influence from individual bias.

Generalizability was enhanced by involving multiple industry professionals from a variety of backgrounds including agency personnel, contractors, and researchers. When interviewing industry professionals, they were asked to think of typical DBB, CM/GC, and DB projects which may preclude unique aspects of non-typical jobs that could reduce generalizability.

In summary, the validity and generalizability were enhanced, and the bias mitigated through the use of industry professionals with extensive domain experience, input from agency and industry personnel and researchers in the formation of the models and in reviewing the content of the models, and the use of a large sample size of case studies for the given population. These multiple validity and bias checks help establish that the contract administration models are reasonable approximations to the actual processes.

\section{RESULTING IDEFO MODELS Of ACM PROCESSES}

The IDEF0 models created for $\mathrm{DBB}, \mathrm{CM} / \mathrm{GC}$, and $\mathrm{DB}$ are multiple pages each; therefore, this paper is limited to showing the node indices and selected levels of the models (Figures 3-8). These figures provide context for understanding the relationships between contract administration functions between hierarchical levels in a single model and comparisons across multiple models. All functions shown are functions performed by the agency. Functions performed by the designer and contractor are not explicitly shown. Later in the paper, Table 3 shows a comparison of all contract administration functions across delivery methods.

Figure 3 shows the upper hierarchical level of the IDEF0 model. The shaded boxes with DBB, CM/GC, and DB below the node indicate this figure applies to all the contracting methods. A shadow around the box node indicates the presence of lower levels in the hierarchy, or what is 
referred to as a parent-child relationship. Many agency sub-functions occur in the levels lower than this first level. Figure 4 shows the next hierarchical level of the IDEF0 model. Again, the shaded boxes below each node indicate when the contract administration function in the node applies to DBB, CM/GC, or DB. This level reveals broad phases identified in this research for contract administration, namely: alignment, design, preconstruction, construction, and closeout. The preconstruction phase occurs simultaneously with design and is identified as a separate phase in order to highlight the different contract administration functions the agency performs for the CM/GC contract. The DB IDEF0 model is similar at this level, except the role of administering preconstruction falls under the DB entity's responsibility. This means the agency is not performing contract administration functions for $\mathrm{CM}$ preconstruction services for $\mathrm{DB}$ as they would be for $\mathrm{CM} / \mathrm{GC}$, so a separate preconstruction phase is not included in DB. The DBB model does not include the preconstruction phase but does include a design phase prior to contractor procurement. The model continues identifying agency contract administration functions for each of the phases. Figure 5 shows an example of the lowest hierarchical level in the IDEF0 model, specifically agency functions for materials management.

Another way to view the details of an IDEF0 model is to look at the node index. A node index is an outline format of the functions in the model. Figure 6 shows the node index for DBB contract administration functions. Figure 7 shows the node index for $\mathrm{CM} / \mathrm{GC}$ contract administration functions and figure 8 shows the node index for DB contract administration functions. Figures 6-8 show the upper or "A0" level and the lower "A\#" phase levels for DBB, $\mathrm{CM} / \mathrm{GC}$, and $\mathrm{DB}$. When the triangles at the left side are pointed down the level directly below that level is revealed in the node index. When the triangles are pointed to the right, this is an indication that there are lower levels for this node, but they are not displayed. Figures 6-8 clearly show that 
design occurs before a contractor is procured in $\mathrm{DBB}$, and preconstruction services is a separate phase in $\mathrm{CM} / \mathrm{GC}$ only. The level below administer design are nearly similar for $\mathrm{CM} / \mathrm{GC}$ and $\mathrm{DB}$ at this level except for the negotiate post-design services function under CM/GC. A detailed comparison of the models is presented in the next section.

\section{ANALYSIS Of RESULTS: COMPARING DELIVERY METHODS}

A primary contribution of this research is a comparison of contract administration functions across DBB, CM/GC, and DB delivery methods. Similarities and differences between agency contract administration functions are shown in Table 3. A larger number of differences occur between DBB and $\mathrm{ACMs}$ than between $\mathrm{CM} / \mathrm{GC}$ and $\mathrm{DB}$. Levels within the model hierarchy are labeled top level, phase level, and lower level. Each level is discussed in turn below.

\section{Top Level Comparisons}

The top level of these IDEF0 model hierarchies is a single function that provides a context for the purpose of the model. For all three contracting methods the focus of these models is contract administration. These models do not address agency activities that occur prior to award of design and construction contracts. That is, preliminary planning or design that occurs prior to contracting with a $\mathrm{CM} / \mathrm{GC}$ or DB is not included. The top level listed in Table 3 corresponds to the IDEF0 model depicted in Figure 2.

\section{Phase Level Comparisons}

In these models, the level directly below the top level is called the phase level, which includes: alignment, design, preconstruction (for $\mathrm{CM} / \mathrm{GC}$ only), construction, and closeout. The main difference when comparing delivery methods at this level is preconstruction, which has contract administration activities in $\mathrm{CM} / \mathrm{GC}$ only. $\mathrm{DBB}$ does not involve the contractor in design. In DB, the contractor is performing similar tasks that a $\mathrm{CM} / \mathrm{GC}$ performs during preconstruction. 
However, in DB there is not a separate contract for preconstruction services, so the DB entity administers these functions instead of the agency. This does not preclude the agency from reviewing submittals and ensuring design compliance in the design phase. There are also differences in the alignment phase. For DBB, the agency can align with the designer during design, but has to wait to align with the builder until the design is complete and a construction contract awarded. For DB, the designer and builder are coming to the project as one entity with one contract, so there is additional responsibility on the DB entity to establish alignment. In the construction phase, quality management and measurement and payment may be performed the same or differently in ACMs compared with DBB. This is discussed further in the description of the construction phase below. The phase level IDEF0 model is depicted in Figure 3.

\section{Lower Level Comparisons}

In the IDEF0 models, a more granular look at contract administration processes is revealed as the hierarchy steps from the phase level to the lower levels. In the levels below the alignment phase, the contract administration functions for $\mathrm{CM} / \mathrm{GC}$ and $\mathrm{DB}$ are similar in many ways; however, they both differ from DBB in that the contractor is brought into alignment during the design. In the levels below the design phase, the contract administration functions that differ are due to the early involvement of the contractor in design (Pellicer et al. 2017). For example, value engineering can look different in each delivery method. During design of a DBB, there is no builder under contract, so value engineering does not get the benefit of the contractor's input until construction, and any cost savings are shared between the agency and contractor. During CM/GC and DB design, the contractor is providing constructability input before design decisions are finalized, so there is no need for value engineering during construction. Also, work packages associated with fast tracking are a feature of $\mathrm{CM} / \mathrm{GC}$ and $\mathrm{DB}$. Furthermore, the agency needs to negotiate post-design services 
with the designer in both $\mathrm{DBB}$ and $\mathrm{CM} / \mathrm{GC}$, but not with $\mathrm{DB}$. Moreover, in DBB, a complete set of project plans and specifications is required for bidding. In $\mathrm{CM} / \mathrm{GC}$ and $\mathrm{DB}$, the plans need to be developed to a state where there is enough information to build the project and fulfill requirements for record drawings, but not to competitively bid the entire project. However, in ACM projects, some work packages may require a detailed bid package with unambiguous interpretation in order to competitively bid the work among subcontractors. In each case the agency holds the contract administration function of managing design documentation, even though the level of design documentation might vary. Contract language and team alignment can help an agency manage design documentation.

The levels below the preconstruction phase is where the agency negotiates with the $\mathrm{CM} / \mathrm{GC}$ to determine the construction price often in the form of a guaranteed maximum price (GMP) or construction agreed upon price (CAP). In contrast, DBB is a low bid price, and DB can be low bid, qualifications, or a hybrid referred to as best value (Alleman et al. 2017a). The preconstruction services are paid by the agency under a $\mathrm{CM} / \mathrm{GC}$ preconstruction services contract. In DB, the proposal price includes contractor involvement in design, though it is not referred to as preconstruction services. In DBB, there are no preconstruction services since the builder has not been contracted when design is occurring.

In the levels below the construction phase, the agency performs many of the same contract administration functions in all three delivery methods. In contrast, when performance specifications are used with DB, the risk of any previously unidentified work required to achieve the original scope is carried by the $\mathrm{DB}$ entity. In contrast, for $\mathrm{DBB}$ and $\mathrm{CM} / \mathrm{GC}$, the agency may be responsible for work that was not identified initially and meets the criteria for additional scope. In the case when an agency decides to add scope beyond the original intent and goals of the project, 
the agency is responsible for the additional cost in all three delivery methods. All projects carry risk and it is helpful if the contract clarifies who is responsible for the various risks. In CM/GC, the agency and the contractor work together to identify risk and negotiate who is responsible for managing and paying for each risk through risk pools. DB contracts with a negotiated GMP may also involve discussions of risk and a negotiated assignment of risk (Tran et al. 2018a; AASHTO 2005; Molenaar et al. 2000). In contrast, in DBB and non-negotiated DB, the contract may clarify how risk is handled for a project, but the risk allocation is decided unilaterally by the agency.

Some construction contract administration functions may or may not vary across delivery methods. For example, some agencies implement quality management in ACMs the same as for a DBB. However, on larger DB projects, some agencies are putting the DB entity in charge of quality control, and the agency performs statistically based sampling for verification. Measurement and payment is another example of a construction contract administration function that might be managed in $\mathrm{CM} / \mathrm{GC}$ and $\mathrm{DB}$ just as an agency manages it in DBB with regular field measurement and reviews of pay applications. Alternatively, an agency may decide a project with a GMP or CAP does not need accurate field measurements, and instead estimates the percent completion for work performed. The functions for managing materials in the IDEF0 model in Figure 4.

In the lower levels of the closeout phase, contract administration functions for DB and $\mathrm{CM} / \mathrm{GC}$ are similar to DBB. However, warranties are not typical of DBB, and when federal funding is involved, they are generally not used in $\mathrm{CM} / \mathrm{GC}$ and $\mathrm{DB}$ either.

\section{DISCUSSION of RESULTS}

The comparison of DBB, CM/GC, and DB IDEF0 models of contract administration functions provides a window into the path for delivering a project from the agency's perspective. If an agency has primarily been using one delivery method, seeing where contract administration 
functions are the same or different can help with deciding whether to use a different delivery method and how to prepare for implementing a different delivery method. This section discusses a few contract administration functions that differ depending on the delivery method. Some of these differences are caused by involving the contractor in design, while other differences relate to quality management and risk assignment. These differences suggest the need for training and organizational change.

A number of ACM contract administration functions are distinguished from DBB due to contractor involvement in design (Touran et al. 2010; Miller et al. 2000). For example, in DBB administer alignment occurs with the agency and designer during design, and then again when the construction contract is awarded to a builder. In $\mathrm{CM} / \mathrm{GC}$ and $\mathrm{DB}$, alignment with the designer and builder occurs before a construction contract is awarded. During the case study interviews, some agencies said they were looking for innovation or cost savings by involving the contractor in design through a $\mathrm{CM} / \mathrm{GC}$ or $\mathrm{DB}$. This relates to the contract administration functions review $C M / G C$ input for design, and through alternative technical concepts which are proposed during DB procurement. The $\mathrm{CM} / \mathrm{GC}$ and the DB perform constructability reviews and iterative budgeting and scheduling. They explore phasing and construction means and methods. This is built into the contracting method. Through the contract administration functions of ensuring design compliance and reviewing design package, the owner observes the impact of contractor involvement in design. The project influence curve (CII 1995) suggests that the earlier in the life of a project that ideas and changes are raised, the less costly they are to implement. Thus, involving the contractor in design through CM/GC and DB (Zhang et al. 2019) is thought by some agencies to foster innovation and cost savings. 
Quality assurance is important in every project regardless of delivery method. All three IDEF0 models (DBB, CM/GC, and DB) include the contract administration function monitor $Q A / Q C$. Although quality assurance is becoming the preferred term (Molenaar et al. 2010), most of the agency representatives from the case study interviews still used the term QA/QC. Most agencies have a long history with DBB and construction manuals that detail their quality processes (Molenaar et al. 2015; Anderson and Damnjanovic 2008; Ernzen and Feeney 2002). However, use of a DBB quality management system for an ACM can be problematic (Molenaar et al. 2010). In the agency case study interviews, agencies indicated they are holding to the agency standards of quality no matter how quality assurance responsibilities are divided. Quality management is important for design as well as construction (Molenaar et al. 2015). Contract administration functions like ensure design compliance and review design package convey the importance of quality in design. Contract administration functions like manage materials and control and inspect work express the importance of quality in construction. During construction, quality sampling and testing may be performed by the agency (or agency's consultant), or the contractor, or by a thirdparty hired by the contractor. Any of these methods can be used with any delivery method, however, the contractor or third-party methods are more common with DB. During the case study interviews, many agencies were reluctant to rely solely on the contractor or the third party hired by the contractor, so the agency was performing additional verification at additional cost to the agency. This suggests that agency inspection staff that is used to coordinating their own sampling and testing may need training on how reassigning this responsibility to the contractor changes their inspection role. Training will be discussed further toward the end of this section.

Every construction project holds risk (Molenaar et al. 2010). Delivery methods approach the assignment of risk in various ways. In DBB, the construction contract is prepared by the agency 
and the agency assigns risk. The CM/GC IDEF0 model contains contract administration functions for review shared risk contingency and review agency contingency. These contingencies are risk pools established based on a risk analysis conducted during preconstruction. Thus, the agency and $\mathrm{CM} / \mathrm{GC}$ are working together during the review $C M / G C$ input for design to establish risk pools or contingency funds for construction. When a DB contract is negotiated, the DB entity performs a risk analysis and negotiates risk assignment with the agency. DB procurement with minimal base design introduces risk related to environmental permitting (AASHTO 2005). In a non-negotiated DB, the agency determines the risk assignment (Xia at al. 2012). Inconsistent application of contingencies has been noted as a problem in delivering transportation projects (Molenaar et al. 2010) and ACMs provide a context for communicating risk allocation. In all delivery methods, the agency should work to get a strong understanding of project risk to be able to assign risk appropriately.

Effective project delivery requires effective training, experience, and appropriate organizational culture. Most transportation agencies in the US have a long history of DBB delivery. Agencies have design, construction, and procurement manuals which serve as resources for training along with guidance that is passed down informally. The need for training is consistent with the literature that notes a cultural, organizational, and process shift to implement ACMs (Minchen et al. 2014; Pietroforte and Miller 2002; Molenaar and Gransberg 2001; Miller et al. 2000). During the case study interviews, some agency representatives encouraged learning through reaching out to other states, asking questions, and participating in peer exchanges. Other agencies had training sessions for staff. Many agencies offered no formal ACM training. Agency use of $\mathrm{CM} / \mathrm{GC}$ and DB is newer than DBB. Not all agencies have ACM manuals, and those that do are still developing and expanding their content. In these situations, outside resources and on-the-job 
training with experienced personnel can help agencies successfully implement ACMs. During the case study interviews, one agency representative advised, "Get familiar with contractor pricing, it's different than agency bid history pricing" which emphasizes the different perspective and knowledge the agency needs when reviewing $\mathrm{CM} / \mathrm{GC}$ construction cost estimates. Contractor involvement in design may trigger training for agency reviewers to be open to new ways of accomplishing project goals, the importance of meeting review deadlines, and focusing on ensuring design compliance. New ways of sharing responsibility for quality may require training for inspectors and a shift in culture to accept data from sources that are different from what was previously used. Training may be needed and processes implemented for improved risk assessment and calculation of risk allowances or contingencies. For any delivery method, training and organizational culture can help reinforce agency processes and best practices for project delivery.

In summary, the results of this research provide a comparison of $\mathrm{DBB}, \mathrm{CM} / \mathrm{GC}$, and $\mathrm{DB}$ contract administration functions through IDEF0 modeling that reveals many similarities and some important differences. A few important differences include contractor involvement during design, quality assurance, and risk assignment. Understanding contract administration functions can help agencies understand the training, process changes, or organizational culture shifts that are needed for effective contract administration of ACMs.

\section{CONCLUSION}

This paper contributes to the existing body of knowledge of highway contract administration by modeling and comparing contract administration functions for $\mathrm{DBB}, \mathrm{CM} / \mathrm{GC}$, and $\mathrm{DB}$. Previous comparisons of delivery methods focused on contract relationships and benefits of each delivery method. The IDEF0 models developed in this research provide a rich understanding of the contract administration functions through exploring their hierarchy and relationships between functions. 
Key parts of the model and node indices are included in this paper while the complete multipage models can be seen in their entirety in Papajohn (2019). The model was tested using the input of industry professionals at various points in the model development process. Results from this research can help agencies in many ways. The models delineate contract administration functions that agencies perform. This allows agencies to see how they will be interacting with the contractor through different delivery methods. Furthermore, knowing about the functions that need to be performed will help agencies assign qualified staff to their projects. It can also help agencies identify areas where staff need training, processes need changing, and organizational culture needs adjusting.

The models focus on five phases: alignment, design, preconstruction (only for $\mathrm{CM} / \mathrm{GC}$ ), construction, and closeout. In alignment, $\mathrm{CM} / \mathrm{GC}$ and $\mathrm{DB}$ differ from DBB by bringing the builder into alignment during design. In design, $\mathrm{CM} / \mathrm{GC}$ and $\mathrm{DB}$ differ from $\mathrm{DBB}$ due to contractor involvement in design. Collaboration between the designer and contractor brings the expertise from both domains together with the goal of fostering innovative and cost-effective ways to design and build projects. In DBB, contractor input on cost, schedule, phasing, constructability, and means and methods does not occur until design is completed. In $\mathrm{CM} / \mathrm{GC}$, the contractor provides input in the preconstruction phase and in DB the contractor provides input during proposal preparation and through the design phase. Additionally, fast tracking can be employed with $\mathrm{CM} / \mathrm{GC}$ and $\mathrm{DB}$, which usually results in early work packages not associated with DBB. The contract administration function review early work packages indicates to an agency that they will need staff capable of performing analysis to determine if work packages are independent from the remaining scope of work, priced properly, and benefit the project. In the preconstruction phase, the agency and the $\mathrm{CM} / \mathrm{GC}$ are involved in an iterative and collaborative process to negotiate a 
contract price. In contrast, DBB is awarded to a low bidder. Additionally, DB can be awarded to a low bidder, a qualified bidder, or a combination of these in a best value. In the construction phase, a key difference of $\mathrm{CM} / \mathrm{GC}$ is the implementation of contingency pools based upon a collaborative identification and allocation of risks. Agency and shared risk pools are not typical in DBB and DB. Quality control may reside with the agency as is typical with DBB, or it may be transferred to the contractor with the agency taking on a quality verification role. Furthermore, review payment invoice is a contract administration function required with all delivery methods. The level to which this function is performed may vary with contract type (e.g., lump sum, GMP, unit price) or by agency practice and preference. In closeout, contract administration functions are generally the same for $\mathrm{DBB}, \mathrm{CM} / \mathrm{GC}$, and $\mathrm{DB}$; however, ACMs provide an opportunity for extended warranties. The differences between $\mathrm{DBB}$ and $\mathrm{ACMs}$ like $\mathrm{CM} / \mathrm{GC}$ and $\mathrm{DB}$ largely rest on integrating the contractor in design and deepening communication between the contractor and the designer and agency throughout the life of a project.

One limitation of this research is the models were developed from the perspective of the agency and agency contract administration functions. Future work could compare delivery methods from the contractor's perspective or the designer's perspective. Another limitation is that the modeling does not detail possible differences that project complexity or project size might introduce into contract administration. Future research could look at determining which contract administration functions contribute the most to project success for projects of various sizes and complexities. Additionally, future research could focus on other types of delivery methods, such as job order contracting, design-build-operate-finance-maintain, and integrated project delivery. This research provides a detailed contract administration structure that facilitates the exploration 
of these and other research endeavors to more effectively address the critical needs related to delivering highway infrastructure.

\section{Acknowledgments}

This research was funded by the National Cooperative Highway Research Program under NCHRP 08-104. The researchers are grateful to the NCHRP research panel for their guidance and to the invaluable contributions of state and federal transportation agency personnel who participated in interviews and data collection.

\section{Data Availability Statement}

Some or all data, models, or code generated or used during the study are available in a repository online in accordance with funder data retention policies. IDEF0 models are available at https://repository.asu.edu/items/53505.

\section{References}

Abotaleb, I. S., El-adaway, I. H., Moussa, M. B. (2019). “Guidelines for administrating and drafting nonpayment owners’ obligation provisions under design-build contracts.” J. Eng. Manage., 10.1061/(ASCE)ME.1943-5479.0000693.

Akinci, B., Kiziltas, S., Ergen, E., Karaesmen, I. Z., and Keceli, F. (2006). “Modeling and analyzing the impact of technology on data capture and transfer processes at construction sites: A case study.” J. Constr. Eng. Manage., 10.1061/ASCE0733-93642006132:11(1148), 1148-1157. Alhazmi, T., and McCaffer, R. (2000). "Project procurement system selection model.” J. Constr. Eng. Manage., 10.1061/(ASCE)0733-9364(2000)126:3(176), 176-184.

Alleman, D., Antoine, A., Gransberg, D., Molenaar, K. (2017a). “A comparison of qualifications based-selection and best value procurement for construction manager/general contractor highway construction." Transportation Research Record, 10.3141/2630-08. 
Alleman, D., Antoine, A., Papajohn, D., and Molenaar, K. (2017b). "Desired versus realized benefits of alternative contracting methods on extreme value highway projects." Proc., Resilient Structures and Sustainable Construction, International Structural and Engineering Society, E. Pellicer, J.M. Adam, V. Yepes, A. Singh and S. Yazdani, eds., ISEC Press, Fargo, ND. Alleman, D., Papajohn, D., Gransberg, D., El Asmar, M., Molenaar, K. (2017c). “An exploration of early work packaging in construction manager/general contractor highway projects." Transportation Research Record, 10.3141/2630-09.

American Association of State Highway and Transportation Officials (AASHTO). (2005).

"Design-build environmental process and level of detail: Eight case studies," http://onlinepubs.trb.org/onlinepubs/archive/NotesDocs/25-25(12)_FR.pdf. (March 3, 2019). Anderson, S. D. and Damnjanovic, I. (2008) "NCHRP Synthesis 379: Selection and evaluation of alternative contracting methods to accelerate project completion," Transportation Research Board of the National Academies, Washington, DC, 68.

Anderson, S., Quiroga, C., Overman, J., Choi, K., Sahu, J., Kermanshachi, S., Goodrum, P., Taylor, T., and Li, Y. (2015). Effective project scoping practices to improve on-time and onbudget delivery of highway projects, NCHRP Project No. 08-88, Transportation Research Board of the National Academies, Washington, DC.

Antoine, A. L., Alleman, D., \& Molenaar, K. R. (2018). "Examination of project duration, project intensity, and timing of cost certainty in highway project delivery methods." J. Manage. Eng., 35(1), 04018049.

Chini, A., Ptschelinzew, L., Minchin, R. E., Zhang, Y., and Shaw, D. (2018). "Industry attitudes toward alternative contracting for highway construction in Florida.” J. Manage. Eng., 10.1061/(ASCE)ME.1943-5479.0000586. 
Chong, H. Y., Balamuralithara, B., and Chong, S. C. (2011). “Construction contract administration in Malaysia using DFD: A conceptual model.” Industrial Manage. \& Data Systems, 10.1108/02635571111182782, 1449-1464.

Colorado Department of Transportation (CDOT). (N.D.) "Project delivery selection matrix." https://www.codot.gov/business/designsupport/innovative/pdsm. (March 3, 2019).

Construction Industry Institute (CII). (1995). "Pre-project planning: Beginning a project the right way," Research Summary 39-1. https://www.constructioninstitute.org/resources/knowledgebase/best-practices/front-end-planning/topics/rt-039. (August 4, 2018).

Design-Build Institute of America (DBIA). (2017). 2017 State Statute Report, https://dbia.org/wp-content/uploads/2018/06/2017-State-Statute-Report-DBIA.pdf. (April 1, 2019).

El-adaway, I. H., Abotaleb, I. S., Eid, M. S., May, S., Netherton, L., and Vest, J. (2018).

"Contract administration guidelines for public infrastructure projects in the United States and Saudi Arabia: Comparative analysis approach.” J. Constr. Eng. Manage.,

10.1061/(ASCE)CO.1943-7862.0001472

Erdogan, B., Anumba, C. J., Bouchlaghem, D., and Nielsen, Y. (2014). “Collaboration environments for construction: Management of organizational changes." J. Manage. Eng., 10.1061/(ASCE)ME.1943-5479.0000231.

Ernzen, J. and Feeney, T. (2002). "Contractor-led quality control and quality assurance plus design-build: Who is watching the quality" Transportation Research Board: J. of the Transportation Research Board, No. 1813, Transportation Research Board of the National Academies, Washington, DC, 253-259. 
Federal Highway Administration (FHWA). (2006). Design-Build effectiveness study, as required by TEA-21 Section 1307(f), Final Report, Washington, DC.

Federal Highway Administration (FHWA). (2016). "Alternative Contracting Methods (ACMs)

Library." http://www.fhwa.dot.gov/construction/contracts/acm/. (Dec. 21, 2016).

Federal Highway Administration (FHWA). (2018). "Alternative contracting method performance in U.S. highway construction,” TechBrief FHWA Publication No. FHWA-HRT-17-100. https://www.fhwa.dot.gov/publications/research/infrastructure/17100/17100.pdf. (Nov. 23, 2018).

Fisher, D. J., Anderson, S. D., and Rahman, S. P. (2000). "Integrating constructability tools into constructability review process." J. Constr. Eng. Manage., 10.1061/(ASCE)07339364(2000)126:2(89), 89-96.

Furnham, A. (1986). "Response bias, social desirability and dissimulation". Personality and Individual Differences. 7 (3): 385-400. 10.1016/0191-8869(86)90014-0.

Gibson, G. E., Jr., Kaczmarowski, J. H., and Lore, H. E., Jr. (1995). “Preproject-planning process for capital facilities."' J. Constr. Eng. Manage., 10.1061/(ASCE)07339364(1995)121:3(312), 312-318.

Gordon, C. M. (1994). "Choosing appropriate construction contracting method." J. Constr. Eng. Manage., 10.1061/(ASCE)0733-9364 (1994)120:1(196), 196-210.

Gransberg, D. D., \& Molenaar, K. R. (2019). "Critical comparison of progressive design-build and construction manager/general contractor project delivery methods. Transportation Research Record, 0361198118822315.

Knowledge Based Systems, Inc. (KSBI) (N.D.a). "IDEF family of methods.” College Station, TX, http://www.idef.com/. (July 30, 2018). 
Knowledge Based Systems, Inc. (KSBI) (N.D.b). "IDEF function modeling method.” College Station, TX, http://www.idef.com/idefo-function_modeling_method/. (July 30, 2018). Konchar, M., and Sanvido, V. (1998). "Comparison of US project delivery systems." J. Constr. Eng. Mgmt., 10.1061/(ASCE)0733-9364(1998)124:6(435).

Law, A. M., and Kelton, W. D. (2000). Simulation modeling and analysis, McGraw-Hill, Boston. Lucko, G. and Rojas, E. M. (2010). "Research validation: Challenges and opportunities in the construction domain." J. Constr. Eng. Manage., 10.1061/(ASCE)CO.1943-7862.0000025. Luu, D. T., Ng, S. T., and Chen, S. E. (2005). "Formulating procurement selection criteria through case-based reasoning approach.” J. Comput. Civil Eng., 10.1061/(ASCE)08873801(2005)19:3(269), 269-276.

Mayer, R. J. (Ed.). (1990). "IDEFØ function modeling: A reconstruction of the original Air Force report." College Station, TX: Knowledge Based Systems, Inc.

Miller, J. B., Garvin, M. J., Ibbs, C. W., and Mahoney, S. E., (2000). "Toward a new paradigm: Simultaneous use of multiple project delivery methods." J. Manage. Eng., 10.1061/(ASCE)0742$597 X(2000) 16: 3(58)$.

Minchin, R. E., Ptschelinzew. L., Migliaccio, G. C., Atkins, K., Warne, T., Hostetler, G., and Asiamah, S. (2014). Guide for Design Management on Design-Build and Construction Manager/General Contractor Projects, NCHRP Report 787, Transportation Research Board of the National Academies, Washington, DC.

Minnesota Department of Transportation (MnDOT). (2008). "Cost Estimation and Cost Management, Technical Reference Manual.” http://dotapp7.dot.state.mn.us/edms/download?docId=670233. (June 28, 2018). 
Molenaar, K. R. (2003). Washington State Department of Transportation design-build pilot project evaluation: A measurement of performance for the process, cost, time, and quality, SR500 Thurston Way Interchange, WSDOT, Seattle, WA.

Molenaar, K. R., Anderson, S., and Schexnayder, C. (2010). "NCHRP report 658: Research report for guidebook for risk analysis tools and management practices to control transportation project cost." http://onlinepubs.trb.org/onlinepubs/nchrp/docs/NCHRP08-60_FR.pdf. (March 4, 2019).

Molenaar, K., Franz, B. (2019). “Revisiting project delivery performance 1998-2018.”

CII/Pankow. https://dbia.org/wp-content/uploads/2018/11/Cost_Performance_ResearchCII_Pankow2018.pdf. (June 7, 2019).

Molenaar, K. R., and Gransberg, D. D. (2001). "Design-builder selection for small highway projects.” J. Manage. Eng., 10.1061/(ASCE)0742-597X(2001)17:4(214).

Molenaar, K. R., Gransberg, D. D., and Sillars, D. N. (2015). Guidebook on alternative quality management systems for highway construction, NCHPR Report 808, Transportation Research Board of the National Academies, Washington, DC.

Molenaar, K. R., Vanegas, J. A., and Martinez, H. (2000). “Appropriate risk allocation in designbuild request for proposals (RFPs)." Proc., Construction Congress VI: Building together for a better tomorrow in an increasingly complex world, ASCE, Reston, VA, 1083-1092.

Moving Ahead for Progress in the 21st Century Act (MAP-21), 112 U.S.C. $\S \S 1303-1304$ (2012).

National Economic Development Organization (NEDO). (1985). Think about building: A successful business customer's guide to using the construction industry, National Economic Development Organization, London. 
National Institute of Standards and Technology (NIST). (1993). Announcing the standard for integration definition for function modeling (IDEFO), draft, Federal Information Processing Standards Publication 183, December 21, 1993, http://www.idef.com/wpcontent/uploads/2016/02/idef0.pdf. (June 5, 2018).

National Cooperative Highway Research Program (NCHRP). (2016). NCHRP 08-104, A guidebook for post-award contract administration for highway projects delivered using alternative contracting methods, (CM/GC and DB guidebooks are forthcoming) http://apps.trb.org/cmsfeed/trbnetprojectdisplay.asp?projectid=4032. (Oct. 7, 2018). Papajohn, D. (2019). “Contract administration functions and tools in design-build and construction manager/general contractor project delivery in U.S. highway construction.” $\mathrm{PhD}$ dissertation, Arizona State University, Tempe, AZ. https://repository.asu.edu/items/53505. (May 31, 2019).

Pellicer, E., Sanz, M. A., Esmaeili, B., \& Molenaar, K. R. (2016). “Exploration of team integration in Spanish multifamily residential building construction.” J. Manage. Eng., 32(5), 10.1061/(ASCE)ME.1943-5479.0000438.

Phillips, C. S. (1999). Construction contract administration, Society for Mining, Metallurgy, and Exploration, Inc., Littleton, CO.

Pietroforte, R., and Miller, J. B. (2002). "Procurement methods for US infrastructure: Historical perspectives and recent trends.” Building Res. \& Information, 10.1080/09613210210159875. Quanji, Z., Zhang, S. and Wang, Y. (2017). "Contractual governance effects on cooperation on construction projects: Multinational approach.” J. Prof. Issues Eng. Ed. Pract. 143(3), 10.1061/(ASCE)EI.1943-5541.0000320. 
Sanvido, V. E., and Norton, K. J. (1994). “Integrated design-process model.'” J. Manage. Eng., 10.1061/(ASCE)9742-597X(1994)10:5(55), 55-62.

Sargent, RG. (2013). "Verification and validation of simulation models." J. Simulation, 10.1057/jos.2012.20.

Scott, D. F. (1974). "Effective contract administration in construction management." Transportation Research Board, J. of the Constr. Div., 100(C02), ASCE, NY, 117-132.

Shannon, R. E. (1998). "Introduction to the art and science of simulation.” Proc. 1998 Winter Simulation Conference, D. J. Medeiros, E. F. Watson, J. S. Carson, and M. S. Manivannan, eds. Shrestha, P., O’Connor, J., and Gibson, G. E., Jr. (2012). “Performance comparison of large design-build and design-bid-build highway projects." J. Constr. Eng. Mgmt., 10.1061/(ASCE)CO.1943-7862.0000390.

Skitmore, R. M., and Marsden, D. E. (1998). "Which procurement system?

Towards a universal procurement selection technique." Constr. Manage. Econ., 6(1), 71-89. Tang, P. and Bittner, R. B. (2014). "Use of value engineering to develop creative design solutions for marine construction projects." Pract. Period. Struct. Des. Constr., 19(1): 129-136, 10.1061/(ASCE)SC.1943-5576.0000184.

Thomas Jr., H. R., Willenbrock, J. H., and Burati J. L., Jr., (1980). “Utilization of contract administration resources." Transportation Research Board, J. of the Constr. Div., 106(C02), ASCE, NY, NY, 117-130.

Touran, A., Gransberg, D. D., and Molenaar, K. R. (2010). “A system for selecting project delivery methods in US airports." J. Airport Manage. 4(4), 305-314. 
Tran, D. Q., Brihac, A., Nguyen, L. D., \& Hoon Kwak, Y. (2018a). "Project cost implications of competitive guaranteed maximum price contracts.” J. Manage. Eng., 34(2),

\subsection{1/(ASCE)ME.1943-5479.0000594.}

Tran, D., Diraviam, G., and Minchin, R. E. (2018b). "Performance of highway design-bid-build and design-build projects by work type.” J. Constr. Eng. Manage., 10.1061/(ASCE)CO.19437862.0001437.

Tran, D., Harper, C. M., Molenaar, K. R., Haddad, N. F., and Scholfield, M. M. (2013). “A project delivery selection matrix for highway design and construction." Transportation Research Record 2347, Transportation Research Board, Washington, DC, 3-10.

Tran, D. Q., Molenaar, K. R., and Alarcön, L. F. (2016). “A hybrid cross-impact approach to predicting cost variance of project delivery decisions for highways.” J. of Infrastructure Systems, 10.1061/(ASCE)IS.1943-555X.0000270, 22(1).

Transportation Research Board (TRB). (2009). Glossary of highway quality assurance terms, Fourth update, May 2009, Transportation Research Circular E-137. Wash., DC, 10.17226/23016. Trigunarysah, B. (2004). “A review of current practice in constructability improvement: Case studies on construction projects in Indonesia.” Constr. Manage. Econ. 22(6): 567-580. 10.1080/0144619042000202870.

Wang, W, Chen, Y, Zhang, S. and Wang, Y. (2018). "Contractual complexity in construction projects: Conceptualization, operationalization, and validation.” Proj. Manage. J., 49(3) 46-61, $10.1171 / 8756972818770589$

Xia, B., Chan, A., Molenaar, K. R., Skitmore, M. (2012). "Determining the appropriate proportion of owner-provided design in design-build contracts: Content analysis approach." J. Constr. Eng. Manage., 10.1061/(ASCE) CO.1943-7862.0000522. 
Zhang, S., Liu, X., Gao, Y., and Ma, P. (2019). "Effect of level of owner-provided design on contractor's design quality in DB/EPC projects." J. Constr. Eng. Manage., 10.1061/(ASCE)CO.1943-7862.0001587.

\section{List of Figures}

Fig. 1. Timeline of significant ACM legislation and initiatives in the United States

Fig. 2. Basic structure of an IDEF0 function model

Fig. 3. Level 0 of $\mathrm{CM} / \mathrm{GC}$ IDEF0 function model. Functions apply to contract methods that are shaded gray.

Fig. 4. Level 1 of the CM/GC IDEF0 functional model showing the main post-award phases

Fig. 5. Level 3 of the CM/GC IDEF0 functional model showing functions for managing materials under the construction phase

Fig. 6. Design-Bid-Build node index

Fig. 7. Construction manager/general contractor node index

Fig. 8. Design-Build node index

Table 1. ACM-related manuals for state transportation agencies in the United States

\begin{tabular}{|l|l|c|}
\hline Manual & States & Total No. \\
\hline DB & $\begin{array}{l}\text { AK, AZ, AR, CA, CO, DC, GA, ID, IL, LA, MD, MA, MN, MT, NY, NC, OH, } \\
\text { TN, TX, UT, VA, VT, WA }\left(\mathrm{MO}^{\mathrm{a}}, \mathrm{WV}^{\mathrm{a}}, \mathrm{OR}^{\mathrm{a}}, \mathrm{SC}^{\mathrm{a}}, \mathrm{SD}^{\mathrm{a}}\right)\end{array}$ & 23 \\
\hline CM/GC & AZ, CO, UT $\left(\mathrm{CT}^{\mathrm{b}}\right)$ & 3 \\
\hline ACM & CA, CO, MI, MN, NV, PA & 6 \\
\hline Construction & All US states and Washington DC & 51 \\
\hline
\end{tabular}

${ }^{\mathrm{a}}$ Related documents, not a complete guidebook

${ }^{\mathrm{b}}$ Project specific documents 
Table 2. Summary of experience of industry professionals used in IDEF0 modeling

\begin{tabular}{|c|l|}
\hline No. & Experience of industry professional \\
\hline 1 & More than 40 years of experience with federal and municipal projects in DBB \& ACMs \\
\hline 2 & More than 38 years of experience in construction of DBB \& ACM heavy civil projects \\
\hline 3 & More than 25 years of research experience and agency work in DBB \& ACMs \\
\hline 4 & More than 22 years of experience with federal and municipal projects in DBB \& ACMs \\
\hline 5 & More than 16 years of experience in consulting and public agency transportation projects \\
\hline 6 & More than 12 years of experience with federal and municipal projects in DBB \& ACMs \\
\hline 7 & More than 10 years of transportation agency and research experience in DBB \& ACMs \\
\hline
\end{tabular}

Table 3. Comparison of agency contract administration functions across delivery methods

\begin{tabular}{|c|c|c|c|}
\hline Agency Contract Administration Function & DBB & CM/GC & DB \\
\hline \multicolumn{4}{|l|}{ Top Level-Context Diagram } \\
\hline Administer contract & $\mathrm{X}$ & $\mathrm{X}$ & $\mathrm{X}$ \\
\hline \multicolumn{4}{|l|}{ Phase Level-Main Processes } \\
\hline Alignment phase & & $\mathrm{X}$ & $\mathrm{X}$ \\
\hline Design phase & $\mathrm{X}$ & $\mathrm{X}$ & $\mathrm{X}$ \\
\hline Preconstruction phase & & $\mathrm{X}$ & \\
\hline Construction phase & $\mathrm{X}$ & $\mathrm{X}$ & $\mathrm{X}$ \\
\hline Closeout phase & $\mathrm{X}$ & $\mathrm{X}$ & $\mathrm{X}$ \\
\hline \multicolumn{4}{|l|}{ Lower Levels-Sub Processes } \\
\hline \multicolumn{4}{|l|}{ Alignment with agency, designer and builder } \\
\hline Conduct kickoff meeting & & $\mathrm{X}$ & $\mathrm{X}$ \\
\hline Administer team alignment meeting & & $\mathrm{X}$ & $\mathrm{X}$ \\
\hline Align project plans & & $\mathrm{X}$ & $\mathrm{X}$ \\
\hline \multicolumn{4}{|l|}{ Administer design } \\
\hline Ensure design compliance & $\mathrm{X}$ & $\mathrm{X}$ & $\mathrm{X}$ \\
\hline Perform life-cycle cost analysis, value engineering, and/or sustainability measures & $\mathrm{X}$ & & \\
\hline Manage work package coordination & & $\mathrm{X}$ & $\mathrm{X}$ \\
\hline Review design package & $\mathrm{X}$ & $\mathrm{X}$ & $\mathrm{X}$ \\
\hline Approve design invoice & $\mathrm{X}$ & $\mathrm{X}$ & $\mathrm{X}$ \\
\hline Manage design documentation & $\mathrm{X}$ & $\mathrm{X}$ & $\mathrm{X}$ \\
\hline Enact a contract modification which impacts design & $\mathrm{X}$ & $\mathrm{X}$ & $\mathrm{X}$ \\
\hline Negotiate post design services & $\mathrm{X}$ & $\mathrm{X}$ & \\
\hline Develop final plan package for bidding & $\mathrm{X}$ & & \\
\hline \multicolumn{4}{|l|}{ Administer CM/GC preconstruction } \\
\hline Review CM/GC input for design & & $\mathrm{X}$ & \\
\hline Review project management plans & & $\mathrm{X}$ & \\
\hline Negotiate GMP (or CAP) & & $\mathrm{X}$ & \\
\hline Approve CM/GC preconstruction invoices & & $\mathrm{X}$ & \\
\hline Enact preconstruction contract modifications & & $\mathrm{X}$ & \\
\hline Manage preconstruction documentation & & $\mathrm{X}$ & \\
\hline \multicolumn{4}{|l|}{ Administer construction } \\
\hline Manage legal relations & $\mathrm{X}$ & $\mathrm{X}$ & $\mathrm{X}$ \\
\hline Manage public relations & $\mathrm{X}$ & $\mathrm{X}$ & $\mathrm{X}$ \\
\hline Manage materials & $\mathrm{X}$ & $\mathrm{X}$ & $\mathrm{X}$ \\
\hline Control and inspect work & $\mathrm{X}$ & $\mathrm{X}$ & $\mathrm{X}$ \\
\hline Review potential additional scope & $\mathrm{X}$ & $\mathrm{X}$ & \\
\hline
\end{tabular}




\begin{tabular}{|c|c|c|c|}
\hline Review shared risk contingency with contractor & & $\mathrm{X}$ & \\
\hline Review agency risk contingency with contractor & & $\mathrm{X}$ & \\
\hline Execute supplemental agreements & $\mathrm{X}$ & $\mathrm{X}$ & $\mathrm{X}$ \\
\hline Resolve disputes & $\mathrm{X}$ & $\mathrm{X}$ & $\mathrm{X}$ \\
\hline Measure progress and pay contractor & $\mathrm{X}$ & $\mathrm{X}$ & $\mathrm{X}$ \\
\hline Acquire project completion documentation & $\mathrm{X}$ & $\mathrm{X}$ & $\mathrm{X}$ \\
\hline Ensure as-builts are being developed & $\mathrm{X}$ & $\mathrm{X}$ & $\mathrm{X}$ \\
\hline \multicolumn{4}{|l|}{ Administer closeout } \\
\hline Conduct final inspection & $\mathrm{X}$ & $\mathrm{X}$ & $\mathrm{X}$ \\
\hline Review final turnover documentation & $\mathrm{X}$ & $\mathrm{X}$ & $\mathrm{X}$ \\
\hline Review invoice for final payment & $\mathrm{X}$ & $\mathrm{X}$ & $\mathrm{X}$ \\
\hline Review corrective action completion & $\mathrm{X}$ & $\mathrm{X}$ & $\mathrm{X}$ \\
\hline Execute contractor release & $\mathrm{X}$ & $\mathrm{X}$ & $\mathrm{X}$ \\
\hline Conduct contractor evaluation and lessons learned & $\mathrm{X}$ & $\mathrm{X}$ & $\mathrm{X}$ \\
\hline Execute warranties & & $\mathrm{X}$ & $\mathrm{X}$ \\
\hline
\end{tabular}

Note: Additional sub-levels are not shown when there are no differences between delivery methods. 


\section{7}

- Statute authorized by Florida to experiment with DB

\section{8}

- Transportation Research Board (TRB) Task Force A2T51-Innovative Contracting Practices established

\section{0}

- Special Experimental Project No. 14 (SEP-14)-Innovative Contracting encouraged states to test innovative contracting approaches such as DB and $\mathrm{CM} / \mathrm{GC}$

\section{6}

- 1996 Federal Acquisitions Reform Act (Clinger-Cohen Act) allowed DB to be used by federal agencies

\section{8}

- Transportation Equity Act for the Twenty First Century (TEA-21) Section 1307(c) identified areas needing development for the implementation of DB

\section{2}

- Federal Regulation Design-Build Contracting Final Rule 23CFR636 allowed DB

\section{5}

- Safe, Accountable, Flexible, Efficient Transportation Equity Act: A Legacy for Users (SAFETEA-LU) Section 1503 broadened the use of DB

\section{1-12}

- Every Day Counts (EDC) 1 Innovations included DB and CM/GC

\section{2}

- Moving Ahead for Progress in the 21st Century Act (MAP-21) Sections 1303 \& 1304 promoted innovative technologies and practices including DB and CM/GC

\section{3-14}

- Every Day Counts (EDC) 2 Innovations included DB and CM/GC

\section{7}

- Federal Regulation CM/GC Contracting Final Rule 23CFR630 \& 635 allowed $\mathrm{CM} / \mathrm{GC}$

Figure 1. Timeline of significant ACM legislation and initiatives in the United States 

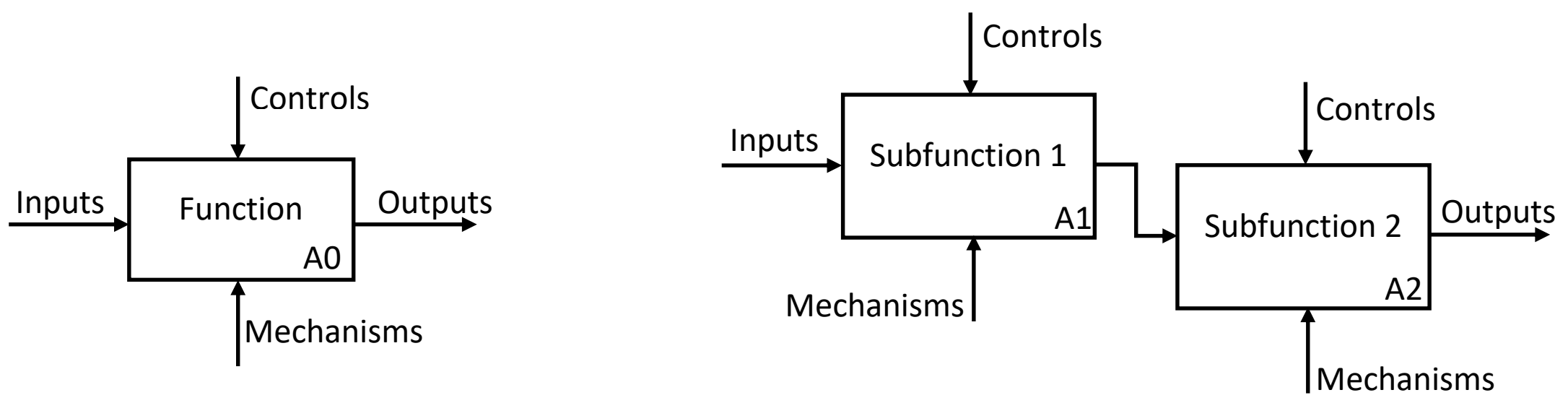

Fig. 2. Graphical depiction of the basic structure of an IDEF0 function model 


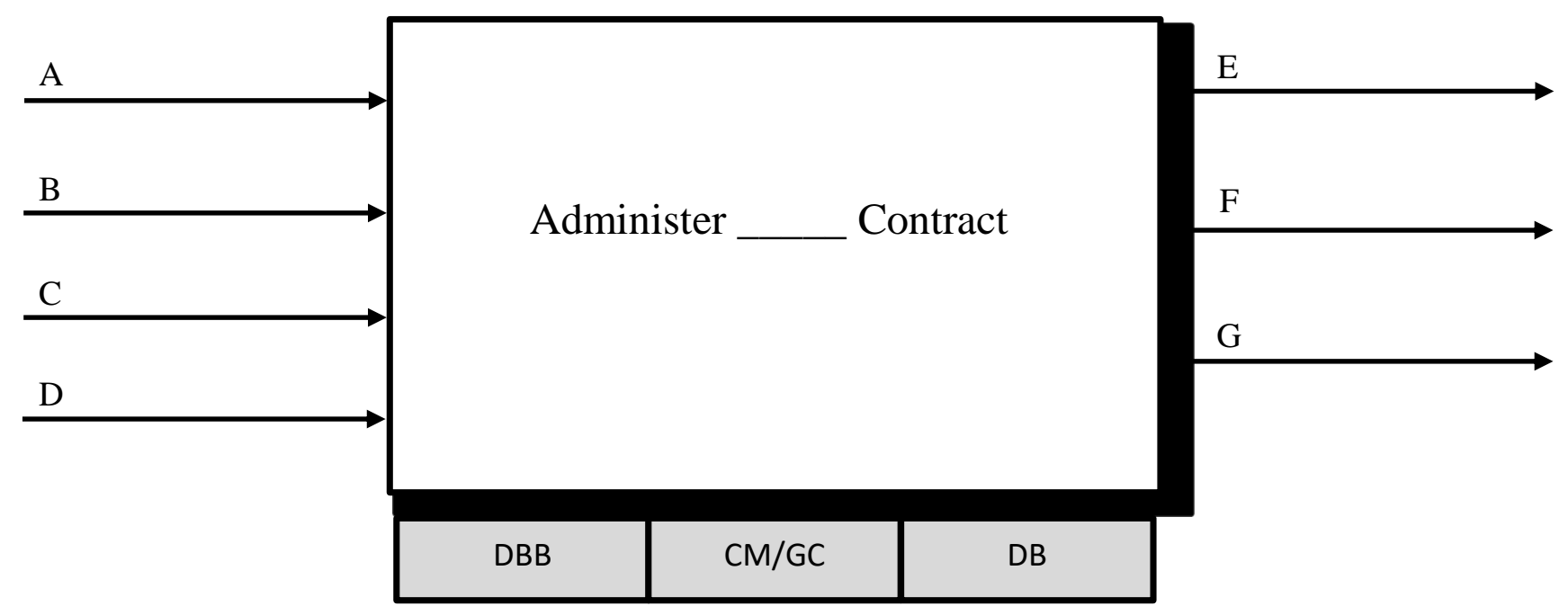

\begin{tabular}{|c|c|}
\hline \multicolumn{2}{|c|}{ Legend } \\
\hline A. CM/GC Contract & E. Project Complete \\
\hline B. Design Contract & F. Contractor Performance \\
\hline C. Agency Directed Change & G. Lessons Learned \\
\hline D. Unforeseen Condition & \\
\hline
\end{tabular}

Fig. 3. Level 0 of DB, CM/GC, and DB IDEF0 function model

Note: Functions apply to contract methods that are shaded gray. 


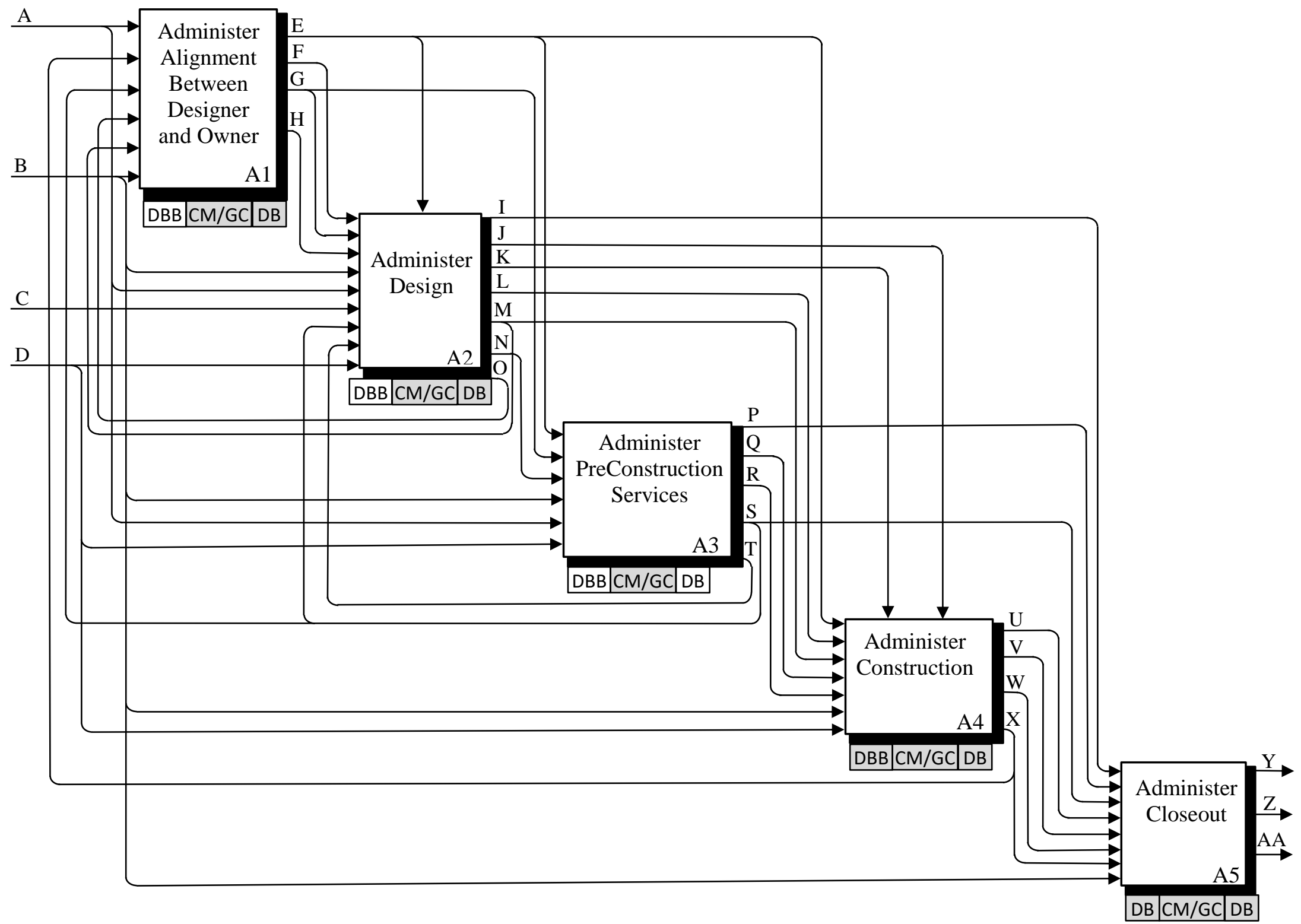




\section{Legend}
A. Design Contract
B. CM/GC Contract
K. Utilities and Permitting Restrictions
C. Agency Directed
D. Unforeseen Conditions Contract
E. Quality Management Plan
F. Cost Model Elements
G. Preliminary Project Management Plans
H. Preliminary Project Plans
I. Design Completion Paperwork
J. Environmental Restrictions

\section{Post Design Services} Contract
M. Work Package 'n' Released for Construction
N. Interim Project Plans
O. Design Contract Modification
P. CM/GC Completion Paperwork
Q. GMP ' $n$ '
R. Final Project Management Plans
S.CM/GC Construction Services
Contract Modification
T. CM/GC Input for Design
U. As-Built Drawings
V. Construction Completion
Paperwork
W. CM/GC Contract
Modification
X Complete Work Package ' $n$ '
Y. Contractor Performance
Z. Lessons Learned
AA. Project Complete

Fig. 4. Level 1 of the DB, CM/GC, and DB IDEF0 functional model showing the main post-award phases

Note: Functions apply to contract methods that are shaded gray. 


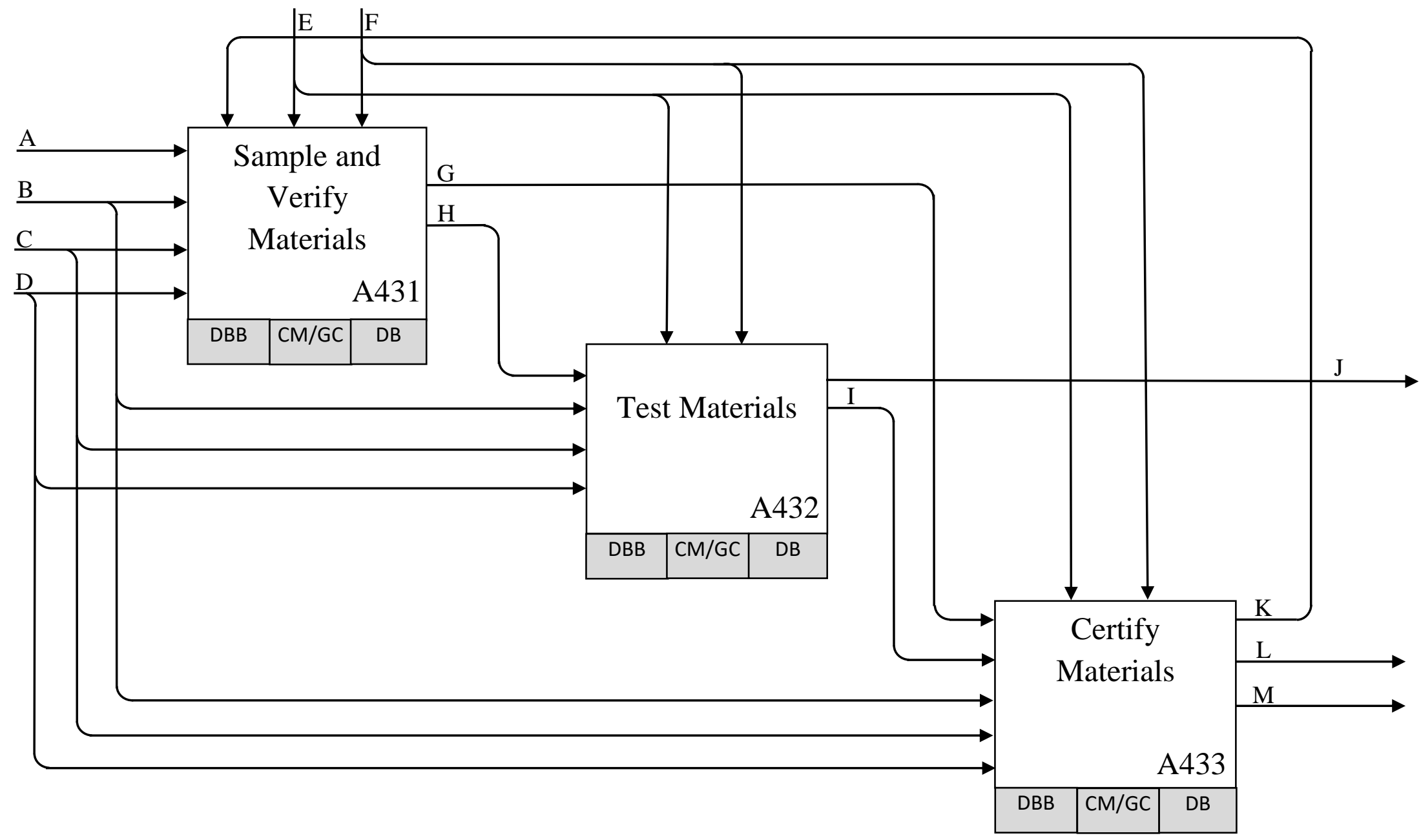




\section{Legend}
A. Final Project Management Plans
H. Material Samples
B. GMP "in"
I. Testing Results
C. Quality Management Plan
J. Material Non-Conformance Found
D. Work Package "in" Released for Construction
K. Reject Material
E. CM/GC Contract Modification
L. Approved Material for Installation
F. CM/GC Contract
M. Material Dispute
G. Field Observations of Certifications

Fig. 5. Level 3 of the DBB, CM/GC, and DB IDEF0 functional model showing functions for managing materials under the construction phase

Note: Functions apply to contract methods that are shaded gray. 
$\nabla$ Administer DBB Contract

$\nabla$ A0: Administer DBB Contract

$\nabla$ A1: Administer Alignment between DOT Team

A11: Conduct Kick-off Meeting

A12: Administer Team Alignment Meeting

-A13: Finalize Project Plans

VA2: Administer DBB Construction

A21: Manage Legal Relations

A22: Manage Public Relations

- A23: Manage Materials

- A24: Control and Inspect Work

A25: Execute Supplemental Agreements

A26: Resolve Disputes

A27: Measure Progress and Pay Contractor

A28: Acquire Project Completion Documentation

A29: Ensure As-Builts are Being Developed by Contractor

VA3: Administer DBB Closeout

- A31: Conduct Final Inspection

-A32: Review Final Turnover Documentation

A33: Review Invoice for Final Payment

A34: Review Corrective Action Completion

A35: Execute Contractor Release

A36: Conduct Contractor Evaluation and Lessons Learned

Fig. 6. Design-Bid-Build node index 


\section{Administer CM/GC Contract}

จ A0: Administer CM/GC Contract

$\nabla$ A1: Administer Alignment between CM/GC, Designer and Owner

A11: Conduct Kick-off Meeting

A12: Administer Team Alignment Meeting ' $n$ '

A13: Align Project Plans

จ A2: Administer CM/GC Design

-A21: Ensure Design Compliance

A22: Manage Work Package Coordination

A23: Review Design Package

A24: Approve Design Invoice

A25: Manage Design Documentation

A26: Enact a Contract Modification which Impacts Design

A27: Negotiate Post-Design Services

V A3: Administer CM/GC PreConstruction Services

A31: Review CM/GC Input for Design

A32: Review Project Management Plans

A33: Negotiate GMP

A34: Approve CM/GC PreConstruction Services Invoices

A35: Enact CM/GC Contract Modification

A36: Manage CM/GC Documentation

จ A4: Administer CM/GC Construction

A41: Manage Legal Relations

A42: Manage Public Relations

- A43: Manage Materials

A44: Control and Inspect Work

A45: Review Potential Additional Scope

A46:Execute Supplemental Agreements

A47: Resolve Dispute

- A48 Measure and Pay Contractor

A49: Acquire Project Completion Documentation

A410: Ensure As-Builts are Being Developed by Designer and CM/GC

V A5: Administer CM/GC Closeout

- A51: Conduct Final Inspection

- A52: Review Final Turnover Documentation

A53: Review Invoice for Final Payment

A54: Review Corrective Action Completion

A55: Execute Contractor Release

A56: Conduct Contractor Evaluation and Lessons Learned

A57: Execute Warranties

Fig. 7. Construction Manager/General Contractor node index 


\section{$\nabla$ Administer DB Contract}

$\checkmark$ A0: Administer DB Contract

₹ A1: Administer Alignment between Design-Builder and DOT

A11: Conduct Kick-off Meeting

A12: Administer Team Alignment Meeting ' $n$ '

- A13: Align Project Plans

VA2: Administer DB Design

A21: Ensure Design Compliance

A22: Manage Work Package Coordination

A23: Review Design Package

A24: Approve Design Invoice

A25: Manage Design Documentation

A26: Enact a Contract Modification which Impacts Design

VA3: Administer DB Construction

A31: Manage Legal Relations

A32: Manage Public Relations

-A33: Manage Material

A34: Control and Inspect Work

A35: Execute Supplemental Agreements

A36: Resolve Disputes

A37: Measure and Pay Contractor

A38: Acquire Project Completion Documentation

A39: Ensure As-Builts are Being Developed by Design-Builder

V A4: Administer DB Closeout

- A41: Conduct Final Inspection

- A42: Review Final Turnover Documentation

A43: Review Invoice for Final Payment

A44: Review Corrective Action Completion

A45: Execute Contractor Release

A46: Conduct Contractor Evaluation and Lessons Learned

A47: Execute Warranties

Fig. 8. Design-Build node index 